\title{
Exploring the Link between Motivation for Course-Choice and Retention in the Architectural Profession: Students' Perspectives
}

\author{
Cynthia Omolola Adeokun
}

Department of Architecture, Covenant University, Km 10 Idiroko Road, Canaan Land, Ota, Ogun State, Nigeria

\author{
Akunnaya Pearl Opoko (Corresponding Author) \\ Department of Architecture, Covenant University, Km 10 Idiroko Road, Canaan Land, Ota \\ Ogun State, Nigeria, e-mail:akunnaya.opoko@covenantuniversity.edu.ng
}

\author{
Doi:10.5901/mjss.2015.v6n6s1p191
}

\begin{abstract}
Studies have identified positive links between students' commitment to the learning process and career aspirations. This paper explored the link between students' commitment to architectural education and their subsequent willingness to remain within the profession. A questionnaire which focused on students' experience of architectural education, experiences in professional offices and intention to practice after graduation was administered to students on the architecture programme in a Nigerian private university in addition to earlier personal statements from the students on why they embarked on the programme. Quantitative data were analysed using descriptive statistics while qualitative data were content analysed. Results indicated a correlation between reasons for choosing architecture and decisions to practice architecture. A gradual drop in desire to practice architecture was observed at higher levels of study compared to the lower levels. To improve retention rate in professional practice, admission process should include a request for a detailed personal statement from applicants, to establish strong congruence between course/major choice and career aspirations.
\end{abstract}

Keywords: architectural education, course-choice, learning process, career aspiration, students.

\section{Introduction}

Several studies have investigated students' commitment to their studies and the outcomes of enrolment are often measured in terms of retention rates on the chosen course (UK National Audit 2007). Studies like Maher and Macallister (2013), Willcoxson and Wynder (2010), Allen and Robbins (2010), Olsen, Spain and Wright (2008) and Tinto (1975) have all indicated that students' entry-level motivations have an effect on how well they stay in the course. In other words, students with greater clarity about why they chose their course and whose course is a direct pathway to their preferred career, have better outcomes in terms of academic performance and retention.

Outcomes have been operationalized in a variety of ways in the literature. Tracey and Robbins (2006) hypothesized that the congruence between interest in a course and outcomes is not a simplistic one, though outcomes can be measured through academic performance via Grade Point Averages (GPA) and retention rates. Also, there are moderating variables that influence the interest-major congruence and outcome relation like environmental constraints and personal flexibility (Tracey, Allen and Robbins 2012), academic performance, students' attitudes and socio-cultural support (Jensen 2011), social support (Eggens, van der Wert and Bosker 2008), study habits and attitudes (Crede and Kuncel 2008) and interest clarity and interest level (Tracey and Robbins 2006). Also the mediating role of students' commitment as expressed through class attendance and high GPAs on the interest-major congruence and outcome relation reported by Dollinger, Matyja and Huber (2008) is consistent with Crede and Kuncel (2008). Onuoha and Unegbu (2013) delved into career aspiration as a predictor of students' performance on cataloguing and classification -a librarianship degree course- in a private university in South-West Nigeria and found that students that wanted a career in library services demonstrated more consistent focus on the utility of the course and commitment, evident as persistence behaviour.

Willcoxson and Wynder (2010) hypothesized that student who choose a career specific major would exhibit more clarity of career direction, have a clearer reason for attending university and demonstrate greater interest in their coursework. This is consistent with the longitudinal studies of medical students in the UK (Parkhouse and Ellin 1988) which showed that less than $1 \%$ of doctors sampled ventured into non-medical careers. Retention rates as a strong 
indicator of institutional health is identified by the National Audit Office, UK (2007), Tracey (2010), Willcoxson and Wynder (2010), Dollinger, Matyja and Huber (2008) and Wessel, Ryan and Oswald (2008). Consequently, this paper delves into the link between motivation for course-choice and retention rates of architecture students as expressed via intentions to remain in the profession by architecture degree students in a private university in South-West Nigeria. Specifically, it addresses the following questions: why do students choose to study architecture? and what factors motivate students to study architecture? Architecture is a career-specific major (Willcoxson and Wynder 2010) since it provides a direct pathway into the profession. Thus, architecture is representative of occupational choice.

The hypothesis explored here stems from the authors' observations of a reduced desire of many students to stay within the profession. This has huge implications for the profession as the cost of training architects is expensive. A low retention in the profession is a 'waste' of resources and often frustrating for students who fail to find fulfilment in the course. The paper's main hypothesis is that the gradual waning of interest in the course has an effect on the desire to remain within the profession and is likely to be connected to the original reason(s) for embarking on the course. Students that are on the course because they want to be architects and who felt competent in design-related subjects at secondary school level are more likely to retain a high interest on the programme and to express a desire to practice architecture. To test the hypothesis - the correlation between career choice, career certainty and potential retention in the profession - a questionnaire was administered to the students focusing on their experience of architectural education and intention to practice architecture on graduation. Earlier, some of the students had provided narratives about why they chose to study architecture.

\section{Theoretical Framework}

A theory, simply put, seeks to identify relationships between concepts and according to Charmaz (2014) may aim for either explanation or understanding. Theories typically try to account for observed phenomena, how these phenomena occur, possibly explain why they occur as observed and help proffer options for intervention. Kohlbacher (2005) contends that case study research lends itself appropriately to the desire to understand social phenomena. Studies within the grounded theory tradition typically seek to explain the 'what', 'how' and 'why' questions. According to Charmaz (2014), seeking answers to 'why' questions range from explanatory generalizations to theorising about causations and abstract understandings of relationships between concepts, particularly from a positivist view which emphasizes the generality of these explanations. Grounded theory from an interpretative perspective emphasises understanding observed phenomena over explanation, which allows for indeterminacy rather than seeking causality and patterns. Hence it is more concerned with meanings in observed actions and more actively engages with the researcher's interpretation of observed phenomena. This is closer to the design of this study.

Relevance of grounded theory to this research flows from the generic preoccupation of many grounded theorists with the aim to construct generalisations from a specific qualitative enquiry and often revolve around data collection. Qualitative researchers according to Charmaz (2014) often emphasise overt behaviour in order to avert charges of bias and of failing to meet traditional quantitative standards of reliability and validity. This study addressed the issue of reliability by using emergent coding derived from preliminary analysis of data (narratives and questionnaires) which was applied to the whole sample, followed by a second review of the coding process for each narrative. In addition, results from the data were compared to existing trends identified from other studies about career-choice and retention on the course or profession. Validity of the results is addressed by comparing results from the questionnaire with the themes from the students' narratives as a form of triangulation, since both explored the same hypothesis as stated earlier.

This paper adopts a position akin to Charmaz's description of grounded theory which 'contains both positivist and interpretivist elements because it relies on empirical observations and depends on the researcher's constructions of them'. We build from specifics, in this case the specifics of why the students in the case study university have an intended low retention rates in the profession and move to general statements while situating them in the context of their construction. So the interest is very much in the clearly defined case study, yet, as Charmaz (2014) states, the interest is in the process of theorizing, which is interpretive. The fundamental contribution of grounded theory methods relevant to this study is its guidance of interpretive theoretical practice.

Data analysis is primarily by content analysis. It draws on existing trends identified from literature review of factors that mediate the process of career-choice and retention on the course/profession, but also identifies themes or ideas expressed in the narrative texts. The content analysis process as explained by Kohlbacher (2005) is a method of examination of data suited to case study research. In this study it involved 'emergent coding' defined by Stemler (2001) as the preliminary examination of data, identification of themes from data, identifying natural boundaries between themes to derive the coding unit and compilation of a 'checklist' for content analysis. 
According to Stemler (2001), content analysis has distinct advantages for this kind of qualitative (textual) analysis because it "is a systematic, replicable technique for compressing many words of text into fewer content categories based on explicit rules of coding". It is useful in dealing with large volumes of data, extending beyond mere word frequency count. The two fatal flaws that destroy the utility of a content analysis identified by Stemler (2001) are faulty definitions of categories and non-mutually exclusive and exhaustive categories. These were avoided by careful syntactic analysis/definition of each code/theme.

\section{Literature Review}

Architecture is a profession. Professional employment is typically distinguished from other paid forms of employment by monopoly power, public service over private gains and use of codes of ethics (Caven and Diop 2012 quoting Barber 1965). The monopoly is typically by virtue of (legal) requirement for registration by a professional body after academic qualification and a specified period of professional practice and commitment to a code of practice that outlines ethical and professional behaviour. The process of formal training also creates an exclusive 'membership' (Erman, Altay and Altay 2004) that according to Caven and Diop (2012) is only attainable by adhering to outlined process, thereby creating a monopoly of power and privileges enjoyable by the select group. Xue and Chen (2004) studied mainland Chinese architects and emphasised that a significant consideration for architects is the need to provide public service by satisfying clients and administrative/planning officers. This typically comes with status, prestige and expectation of financial compensation for the long process of training and experience.

Full registration process involves a combination of formal educational training usually in a university and practical experience gained in an architectural office during and after completion of formal education. In Nigeria, this takes a minimum of eight years. This is comparable with what exists in other countries like South Africa, Ghana, the UK and France (SAIA website, Instiful 2010, Caven and Diop 2012). Nonetheless, similarities in duration of training operate within cultural and structural differences hence reasons for choosing architecture and remaining in architecture may vary and is worth reviewing.

\subsection{Choice of Architecture as a Career}

Several studies like Nelson (1974) and Shields \& Shrestha (2011) have examined reasons students choose to study architecture. While many have a gendered perspective, most focus on traditional rewards like power, status, recognition and financial rewards that may accrue from a profession. Recent research in developed countries according to Caven and Diop (2012) identified increased vulnerability of the construction industry with higher employment insecurity and lower financial compensation particularly in comparison with other professions like law and medicine. They identified three main reasons why practising architects interviewed in the UK and France gave for becoming architects as childhood influences through an interest in construction and design, building and making 'things' and influence of family and friends especially construction industry professionals. This is consistent with Nelson Jr. (1974) and (Kisi, Shields and Shrestha 2011) who also identified a significant influence of family and friends on the decision to study architecture.

The third most common reason for choosing architecture in Caven and Diop (2012) is drawing competence, though none of their respondents had carefully researched the profession prior to embarking on the architectural programme. Edwards and Quinter (2011) studied secondary school students in Kenya and found that the opportunity to apply skills and knowledge, personal interests, learning experiences and advancement opportunities influenced career choice.

A study of Danish students (Kolmos, Mejlgaard, Haase and Holgaard 2013) 10\% of which were design discipline students (including architecture and design), revealed five key motivations for choosing career-specific disciplines to include intrinsic, social good, financial, parental and mentoring. That study found no significant gendered difference for these motivations within the design sub-discipline and although financial motivation was found to be a major reason for coming into design (architecture inclusive) it was not the most mentioned reason. The strength of non-financial considerations is supported by Xue and Chen (2004) who found that less than $40 \%$ of Chinese architects sampled would have chosen a more financially rewarding career than architecture. Non-financial motivations such as aptitude and ability are also highlighted in Parkhouse and Ellin (1988) as important motivators of career choice immediately after graduation.

Overall, the complexity of reasons why students in tertiary education chose their course of study is obvious from the existing literature. The effect of individual ability/talent, knowing people in the profession prior to commencement of study, desire to render public service or leave a legacy and anticipated financial compensation all have a clear effect on course/career choice. 


\subsection{Rewards from Architectural Career}

Studies like Caven and Diop (2012) and Silverman (2004) argue that in assessing people's choice to remain in architecture, it is worth looking into the role of non-financial rewards like the ability to be part of an informal network which helps build clientele, autonomy and flexibility of one's time and opportunities to achieve recognition by creating aesthetic objects which are visible and useful to society. These intangible rewards contribute to mitigate poor extrinsic rewards like job insecurity, low earnings and intense competition for projects.

Stevens (1996) theoretical analysis of over 2,500 famous and distinguished architects from the 1400 s to 1940 s also makes important distinctions between categories of architects, identifying that while 'fame' for the minority group of eminent architects is more driven by reputation based on intellectual or creative ability, for the majority of the architectural population termed 'workaday' architects, the essential reward is money and satisfaction from doing a good job for clients.

\subsection{The 'Experience' of Architectural Study}

The long duration and nature of architectural training may influence students' perception of the profession. Architectural training in Nigeria principally happens in universities as a two-tier under-graduate Bachelor of Science (B.Sc.) and postgraduate Master of Science (M.Sc.) degree programmes, with a 4-year and 2-year structure. Exposure to professional practice occurs during short stints of Industrial Training (IT) after the second and third years, a format birthed from that of the UK.

The experience of architectural education in Nigeria includes heavy workloads which demand several hours working on simulated real-life design projects, dominance of the design studio and the jury or defence where students present their designs for evaluation by a panel of jurors and emphasis on design and 'buildability' over business awareness. These aspects are highlighted as negative aspects (Caven and Diop 2012) or as 'not so negative' signs of 'toughness' and a necessary requisite to the practical experience aspect which most registration processes require. In fact, the overall training of an architect according to several writers like Khan (1987) must further integrate academic education with practical experience on a construction site in order to fully prepare architectural students for postgraduation life.

The foregoing literature review suggests existence of similarities in the duration and rigours of architectural training across the globe. They also reveal several reasons why students study architecture which can be summarised as financial and non-financial considerations. However, there does not seem to be a consensus as to the strength of influence of the factors identified. Moreover, most of the studies have focused on developed countries thus revealing a dearth of studies in this area in developing countries like Nigeria. This paper intends to empirically contribute to filling this obvious knowledge gap.

\section{Method}

The case study was Covenant University, Ota, South-West Nigeria, a private fee-paying Christian university offering career-specific courses like architecture and engineering. Covenant University was chosen because it is the first private university to offer architecture in the country and currently has the largest number of students studying architecture compared to other private schools in the country. Data was obtained from architecture students on the two-tier degree programme using a questionnaire focused on students' experience of coursework, industrial training segment of the course and intention to practice architecture after graduation. In their second year of study, current second and third year students had been asked to provide a 'narrative' (in their own words) of why they chose to study architecture. The narratives were written in 2012 and 2013 respectively, while the questionnaire was administered in 2014. According to Kohlbacher (2005) "the combination and mixing of different research methods bears an enormous potential for the advancement of social research", hence the adoption of multiple approaches here.

The total population of three hundred and fifty (350) undergraduate and post-graduate architecture students constituted the sample frame, with a male and female proportion of $71.6 \%$ and $28.4 \%$ respectively. The questionnaire was administered to all the students. Participation was voluntary. The questionnaire was divided into sections. The first part focused on respondents' personal characteristics, the second part collected data on family characteristics including parents' socio-economic status; the third part collected data on why respondents chose to study architecture and the fourth part focused on respondents' educational and career aspirations. Finally respondents were asked "what will encourage students to practice?" One hundred and forty-one (141) questionnaires ( $40 \%$ of the sample frame) were returned. One hundred and thirty-two (132) students from the current second and third year students participated in the 
narrative writing exercise out of a total of one hundred and forty-six (146), representing $90.4 \%$ of the combined second and third year population. Quantitative data were analysed using descriptive statistics while qualitative data obtained through the interviews were content analysed to identify unifying themes.

\section{Results}

The results from the narratives and questionnaires are presented in this section.

\subsection{Sample Profile}

Thirty-two (32) students in the first year, thirty-six (36) in second year, and fifty-six (56) students in the third year of the undergraduate programme responded to the questionnaire while only one student in fourth year responded. This was discarded from the results since it was not considered representative of the class. Seventeen (17) representing $56 \%$ of the first year post-graduate students responded while none of the second year post-graduate students participated. Over $90 \%$ of the respondents were under 20 years old with a relatively even gender split ( $54.1 \%$ male and $45.4 \%$ female) which is higher than the sample frame gender split. Majority of the respondents $(61 \%)$ were Yoruba speaking, $13.5 \%$ were Ibo while 2.8\% were Hausa representing the three main ethnic groups in Nigeria. In addition, $22 \%$ were from other ethnic groups in Nigeria. For most of the students, both parents have at least a first degree $(93.6 \%$ of the fathers and $92.9 \%$ of the mothers) and over $90 \%$ of these parents/guardians are employed. Majority of the students classified their families as at least middle income, with only $2.1 \%$ describing their families as low-income. Interestingly, a third of the respondents have fathers, and $4.3 \%$ have mothers who work in the construction industry. The narrative study is drawn from a similar socio-economic profile. However, the narratives featured a gender split that is consistent with the sample frame.

\subsection{Career Preferences from the Questionnaire Results}

About $40 \%$ of the respondents had received some counselling prior to choosing architecture. Of these, $28.1 \%$ received advice from a guidance counsellor. However, the most popular form of career counselling came from parents/guardians $(51 \%)$ and interaction with an architect $(47.4 \%)$. Other sources of advice were teachers $(19.3 \%)$, friends $(11 \%)$ and other professionals in the construction industry $(2 \%)$. The question about whether the students liked architecture prior to commencing their study revealed that $17 \%$ did not like architecture while $5 \%$ stated that the decision to study architecture was their parents'. The most popular self-motivated reason for choosing architecture as shown in Table 1 is the ability to draw (57.4\%) while love for aesthetically pleasing buildings was the second most popular reason (39\%). This is followed by the prestige attached to the profession $(27 \%)$, potential to generate wealth $(24 \%)$ and desire to avoid a course that involved a lot of reading (14.2\%).

Table 1 Students' reasons for choosing architecture

\begin{tabular}{lcc}
\hline Reasons for choosing architecture & Frequencies (n) & Percentage (\%) \\
\hline Ability to draw & 81 & 57.4 \\
Like aesthetically pleasing buildings & 55 & 39 \\
Prestige & 38 & 27.0 \\
Potential for wealth & 34 & 24.1 \\
Don't like to read & 20 & 14.2 \\
Parent's choice & 13 & 9.2 \\
\hline
\end{tabular}

In addition, it was found that several students also reported a mixture of reasons as well as non-architectural professional goals as highlighted in the excerpt below:

"It suits my ability and does not involve much calculation. I would love to practice for a while and then go into business."

Year 2, male student (2013)

It is of interest that forty-three (43) respondents representing $34 \%$ of the under-graduate respondents do not intend to continue onto the M.Sc. programme, which is a mandatory part of the training required to become a fully qualified architect in Nigeria. This is a significant attrition rate between the B.Sc. and M.Sc. programmes, although it is noted that 
some students go on to complete their programme in other universities. A little over half of the sample $(59 \%)$ intends to practice architecture while close to a third of the 141 students were undecided about whether to practice architecture after graduation. The reasons for not wishing to practice or being undecided about practicing are presented in Table 2 . These include a desire to pursue other careers outside the construction industry such as business, fashion, music, politics and real estate $(59.6 \%)$, the tedium, that is, the long working hours and the workload $(38.1 \%)$ and a lack of interest in design/construction (34.9\%). Other reasons include concerns about low financial reward (19.7\%), limited employment prospects (17.5\%) and negative feedback from other people (12.7\%).

Table 2. Why respondents do not wish to practice architecture

\begin{tabular}{lcc}
\hline Why do you not wish to practice Architecture? & Frequencies $(\mathrm{n})$ & Percentage $(\%)$ \\
\hline Desire for other careers & 84 & 59.6 \\
It is very tedious(long working hours and workload) & 24 & 38.1 \\
Lack of interest in Design/Construction & 22 & 34.9 \\
Low financial reward & 12 & 19.7 \\
Limited job prospects & 11 & 17.5 \\
Negative reports from other people & 8 & 12.7 \\
\hline
\end{tabular}

Regarding what could be done to improve students' commitment to the course, respondents' responses included the need for improved awareness of specialisation options, more stimulating and creative teaching (which are essentially comments about quality of education) and comments about the state of the profession in the form of requests for better pay and creation of more job opportunities (see Table 3). It will be recalled that these are among the reasons why some students are averse to staying on in the profession.

Table 3. What would encourage students to practice?

\begin{tabular}{lcc}
\hline What would encourage students to practice? & Frequencies $(\mathrm{n})$ & Percentage $(\%)$ \\
\hline Improved awareness of Specialisation options & 75 & 53.2 \\
More creative, stimulating teaching & 50 & 35.5 \\
Better pay & 35 & 24.8 \\
Enhanced job opportunities & 31 & 22.0 \\
\hline
\end{tabular}

The study also delved into the fact that students are mandated to participate in the industrial training programme, yet only eighty-two (82) of the respondents (58.2\%) have worked in an architect's office while seventy-one (71) respondents had worked on a construction site. However, the majority $(85.4 \%)$ of those who worked in an architect's office reported having enjoyed it. The most enjoyed aspect of working in an architect's office were the office environment and staff interaction, while the observation of site processes was the most enjoyed aspect of working in a construction firm.

\subsection{Career Preferences from the Narratives}

The results of the narratives reinforced some of the findings from the questionnaire and indicated that some of the findings were consistent over the three years during which data were gathered. Content analysis of the narratives revealed a total of thirty-four (34) categories of reasons why students chose architecture. In order to reduce and streamline the categories to a manageable size, they were further subsumed into nine (9) distinct themes based on all the number of times each category was mentioned by each respondent. The nine themes include interest and ability (36\%), people related (advice/instructions, 18.4\%), and personality related reasons (being creative and imaginative, to give back to community and humanity, to leave a legacy and express ideas through buildings and a love for perfection/details, $16.0 \%$ ). Characteristics of the profession (the requirement for creativity, teamwork, attention to detail/precision, thinking process and to confront or take advantage of gender related features of the profession) was $8 \%$ of the theme responses, inspiration (divine, human and even movies or buildings) was $6.8 \%$, avoidance of subjects/conditions (avoidance of science subjects such as chemistry, theoretical work, going to a public university and higher entry requirements at public universities) was $5.6 \%$. Other themes identified are the termination of original goals (the abandonment of other courses due to failure to gain entry to such subjects, or on health grounds) which was $4.0 \%$, desire to fulfil a vision/dream (design of iconic buildings) was $2.8 \%$ and having an interest in architecture, but also being influenced by peoples' advice (people and interest) was $2 \%$. 
The main reasons for choosing architecture were consistent in both samples. In the 2012 sample, interest and ability, personality of the student, people related advice/instructions and the characteristics of the profession were the most common reasons while in 2013, interest and ability, people related advice/instructions, personality of the student, avoidance of subjects and termination of original goals were the most common reasons for studying architecture (see Fig.1)

Architecture was not the first choice for $11 \%$ of the respondents with only minor variation in the 2012 and 2013 samples (13\% and $9 \%$ respectively). There was some variation in the number of students who were influenced by counselling or intervention from other people $(2012 ; 13 \%$ and $2013 ; 23 \%)$ which is included in the people related (advice/instructions) theme and constituted an overall total of $18.4 \%$ of the themes. A similar variation in the number of students who mentioned personality related reasons was also found, with $18 \%$ of the 2012 study and $11 \%$ of the 2013 study referring to such motivations (overall total of $15 \%$ ). References to the avoidance of subjects and the termination of original goals (see excerpt below) often stemmed from negative feelings/situations, like the preferred choice being considered unacceptable to the student's parents or is unavailable in Nigeria:

"I don't love architecture...I hope to pursue a second degree in history and international relations and maybe take a course in design because I still love art, it is still a way of channelling my emotions and imagination but I will never use it professionally".

Year 2, female student (2012/no. 059)

A mixture of reasons for choosing architecture was also common in many of the responses and the effects of selfefficacy and the influence of friends and relatives in the construction industry are evident as reflected in the quote below:

“..Art was a hobby of mine...My ambitions changed as frequent as the seasons...My aunt was a definite influence in my decision of architecture, she is the pioneer and only female Rear Admiral in West Africa and one of the handful of female Rear Admirals in Africa as a whole, and she is a proud architect". Year 2, Male student (2012/ no. 001)

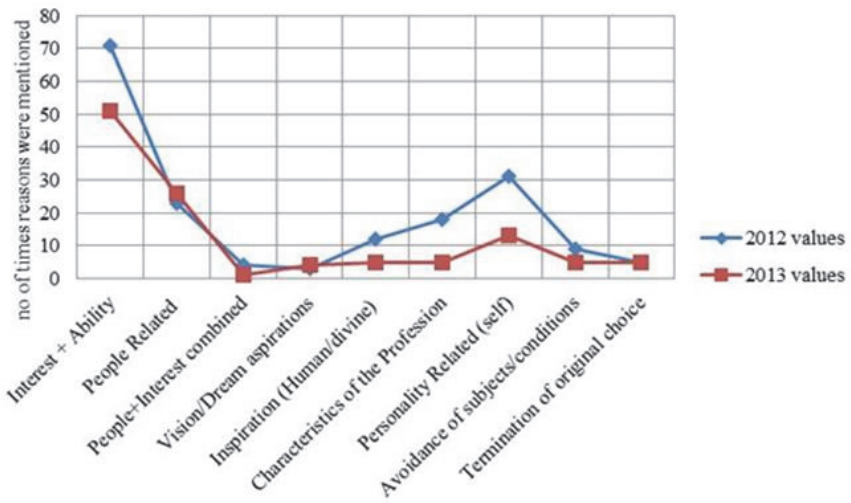

Figure 1: Reasons for choosing architecture from narratives

Some themes reflected the 30/70 female: male sample frame split (interest and ability, people related theme, avoidance of subjects, personality related, and characteristics of the profession), others showed an even split (inspiration motives) but only a few were gender specific (male bias- vision/dream, people and interest and female bias- termination of original goals).

\section{Discussions}

While the majority of the students claimed they liked architecture prior to commencing their studies, the range of themes identified in the narrative (nine themes) and questionnaire (six themes) revealed more complex reasons for choosing a career-specific course such as architecture. The main reasons that influenced the desire to remain (retention) are discussed below. 
There is a distinction between reasons that are an affirmation of the course choice (interest and ability, visions/dreams, inspiration, personality related theme and characteristics of the profession) which constituted $69.6 \%$ of motivations for choosing architecture in the narratives and reasons with negative connotations. However, the positive reasons, inclusive of the interest and ability theme (34\% of the questionnaire responses) were not sufficient to generate a higher percentage of students wishing to proceed into the profession after graduation. When the finding stated in Dollinger, Matyja and Huber (2008) that ability and past performance explained three times more variance in examination performance than students' behaviour and choice is considered, it is suggested that the interest and ability component identified within this case study may be low and the recruitment process should focus on increasing the percentage of the entry intake that is based on interest and ability.

Two fairly unusual positive reasons mentioned in the narrative study were references to human/divine inspiration $(6.8 \%)$ and references to the influence of specific visions/dreams $(2.8 \%)$. These are quite logical when the fact that the case study is a Christian university is considered. It is noted that while these were a small percentage of the overall number of cases $(9.6 \%)$, almost all claim to be very happy and certain of their career choice. Conversely, negative sentiments such as desires to do other courses (11.3\%), being compelled to do architecture (2.5\%), a desire to avoid other subjects (the avoidance theme- $5.6 \%$ ) and the termination of original goals $(4.0 \%)$ are likely to 'feed' ambivalence as the course progresses.

The results showed that $40 \%$ of questionnaire respondents and $18.4 \%$ of the narratives had some form of counselling influence on their career choice, however it coincided with $44.7 \%$ of the students in the questionnaire study expressing a desire to leave the profession or being undecided about continuing. This would suggest that the counselling received prior to course-choice was not sufficient to provide better insight into the rigours and benefits of being an architect. It also contrasts with high retention rates that typically occur with students on vocational subjects such as medicine, law, education and architecture, stated in Purcell et. al. (2009) which also included a sample of over 2500 architecture, building and planning students and affirmed that counselling can improve retention rates. External influence through family/friends/mentors is well documented in literature as stated earlier (Kisi, Shields and Shrestha 2011; Nelson Jr. 1974) and is partly why $17 \%$ of the questionnaire respondents and $11 \%$ of the narratives stated either a dislike for architecture or that it was not their first choice course of study, yet ended up studying architecture (external influence can be positive or negative). As a result, the low projected retention rate (58\%) and the significant numbers that desire other careers, indicate that although interest has a positive impact on outcomes, it was not the only determinant of students' commitment in this case study. The increased ambivalence about architecture is also evident in the numbers of students that intend to go into non-construction industry careers.

The characteristics of the profession were expressed variously in the narratives as a desire to make money, to be self-employed, for fame, prestige, power, a love for travel, and a desire to shape Nigeria's aesthetic landscape. However, greater mention was made of some of these in the questionnaire (potential for wealth, prestige and a love of aesthetically pleasing buildings). Some of these motivations for choosing a career pathway are also evident in literature (Kolmos, Mejlgaard, Haase and Holgaard 2013, Xue and Chen 2004) but are rarely the primal reason for choosing architecture. Both questionnaire and narrative results showed that the perceived characteristics of the profession have an impact on choice. The questionnaire results suggest that some of the perceived negative qualities of the profession (e.g. tedium and low financial rewards) cited as major disincentives ( $28.6 \%$ of the negative reasons) over time may have influenced many to contemplate not going into the profession.

Positive characteristics such as the desire to make money or to attain fame seemed insufficient to stem the drop in the numbers wishing to remain in the profession and this drop in interest is perhaps shaped by insights gained during industrial training, interaction with others and by direct feedback from some of the parents that work in the construction industry. This compares with the findings of the Smith (1992) study that the incorporation of internship programmes into Sociology degree programmes (a non-career specific course) helped students significantly to clarify career choices, by providing first-hand information on occupations and increasing confidence in the ability to choose. However, the exposure can also lead interns to consider other courses if they discover that their proposed career did not provide the anticipated rewards. The Smith's (1992) finding suggests that exposure provided by industrial training/internship programmes can also have a disillusioning effect on the respondent and lessen staying power if anticipated rewards are not met (Caven and Diop 2013, Silverman 2004).

The perception of architecture as a well-paid profession in Nigeria as expressed in the questionnaire is perhaps influenced by the fact that Nigeria's civil service salary scale which ranges from Grade level 1-17, starts all graduates (including medical doctors) at grade 8, but architects start on grade 9. Professionals cannot proceed beyond grade 12, except those with professional registration (e.g. registered architects). Similarly, in the private sector, architects have higher entry salaries than lawyers and engineers but earn lower salaries than medical doctors. 
The role of the individual's personality in the choice process has also been referred to in literature either in terms of social integration and personality (Jensen 2011, Tinto 1975) or perceived major fit (Tracey, Allen and Robbins 2012, Wessel, Ryan and Oswald 2008, Tracey and Robbins 2006). Correspondingly, the narratives revealed that some students chose architecture in order to express aspects of their own personality. The personality theme included choosing a career in order to express creativity and imagination, to give back to the community, to leave a legacy, express ideas through buildings and a love for perfection/details. It was also implicit in the request for more creative teaching in response to the question 'What will encourage students to practice?' Based on the literature review and the results of the questionnaire and narratives, a better fit between personality and the programme will help retain a student's commitment and should also be assessed during course entry interviews.

Several of the narrative themes did not show a gender bias, although three female students chose architecture in search of a female-friendly course or as a personal goal to challenge a perceived male bias in the profession. Similar proportions of males and females expressed a desire to leave the profession from the questionnaire results, after the 30:70 gender spilt is taken into consideration. In addition, the reasons given for not wishing to stay on in the profession did not show much gendered differences. The main reasons for not wishing to practice architecture reported in this paper (a wish to pursue other careers outside the construction industry, long working hours and the workload, a lack of interest in design/construction, low financial rewards, limited employment prospects and negative feedback from other people) also overlapped with the findings in the De Graft-Johnson, Manley and Greed (2003) study into why women leave architecture that included low pay, long working hours, limited areas of work and the possibility of more job satisfaction elsewhere. This lack of strong gender distinction in our study with regards to the intention to remain in the construction industry is however consistent with the finding in Tracey (2010) that there were no gender differences in the main effects between interest and career certainty, but contrary to the finding of strong gender bias in the choice of a secretarial course reported by Igbinedion (2011).

\section{Conclusions - The Role of 'Pure' and External Motivations}

The questionnaire and narrative studies provided a more nuanced understanding of why students embark on architecture and their decisions to stay in the profession. The hypothesis that students who chose architecture by their free will and who have a perceived ability in design-related subjects are more likely to stay on in the profession is supported by the findings of this study but mediated by issues such as the ability to sustain their interest (commitment), the positive (and affirmative) reasons discussed above and by financial, socio-cultural barriers identified in (Jensen, 2011), though this is less of an issue in this relatively socio-culturally homogeneous sample. This was also quite consistent with the Allen and Robbins (2010) finding that higher levels of interest-major congruence lead to the greater likelihood of attaining a degree in a timely fashion (and it is suggested will result in greater retention rates within the profession itself).

Entry intake based on interest and ability motivations should be increased, as these have a positive impact on retention rates based on this study and on other literature identified in this research. However, to identify those who choose architecture for the external (negative) motivations would require more creative assessment strategies such as the use of role play, practical scenario-based projects, a request for a narrative and sample portfolio of works/projects that reflect creative flair.

The limited benefits of pre-choice counselling on outputs noted in this study can be improved by the provision of better career advice prior to students embarking on tertiary education. A detailed written personal statement from the students should also be assessed during the entry interview typically conducted at Covenant University and other universities in Nigeria to increase the fit between career choice and interest and ability. Finally, 'pure' and 'external' motivations affect outputs, and pure (positive) motivations are more likely to reinforce students' commitment.

\section{Limitations and Further Research}

The fact that the data presented is from a single institution is mitigated by the longitudinal dimension of the studies, but there is a need to investigate the links between career choice and low intention rates using other case studies, as a lot of investment goes into the training of architects.

\section{References}

Allen, J., \& Robbins, S. (2010). Effects of Interest-Major Congruence, Motivation, and Academic Performance on Timely Degree Attainment. Journal of Counselling Psychology, 57(1), 23-35. 
Caven, V. \& Diop, M. (2012). Architecture: a 'rewarding' career? An Anglo-French comparative study of intrinsic rewards in the architecture profession. Construction Management and Economics, 30(7), 513-523.

Charmaz, K. (2014). Constructing Grounded Theory. Los Angeles: Sage Publications Ltd.

Christie, H., Munro, M. \& Fisher, T. (2004). Leaving University Early: exploring the differences between continuing and non-continuing students. Studies in Higher Education, 29(5), 616-636.

Crede, M. \& Kuncel, N. R. (2008). Study Habits, Skills, and Attitudes: The third pillar supporting collegiate academic performance. Perspectives on Psychological Science, 3(6), 425-453.

De Graft-Johnson, A., Manley, S. \& Greed, C. (2003). Why Do Women Leave Architecture? Research Project funded by the RIBA and match funded by the University of the West of England.

Dollinger, S. J., Matyja, A. M. \& Huber, J. L. (2008). Which Factors Best Account for Academic Success: Those which college students can control or those they cannot? Journal of Research in Personality, 42, 872-885.

Edwards, K. \& Quinter, M. (2011). Factors Influencing Students Career Choices Among Secondary School students in Kisumu Municipality, Kenya. Journal of Emerging Trends in Educational Research and Policy Studies (JETERAPS) 2(2), 81-87.

Eggens, L., Van Der Werf, M. P. C. \& Bosker, R. J. (2008). The influence of Personal Networks and Social Support on Study Attainment of Students in University Education. Higher Education , 55(5), 553-573.

Erman, T., Altay, B. \& Altay, C., (2004). Architects and the Architectural Profession in the Turkish Context. Journal of Architectural Education, 58(2), 46-53.

Fuentes-del-Burgo, J. \& Navarro-Astor, E. (2013) Do Educational Mismatches Influence Job Satisfaction? In Smith, S. D. and AhiagaDagbui, D. D. (Eds.), Procs 29th Annual ARCOM Conference, 2-4 September 2013 (pp. 237-247). Reading: Association of Researchers in Construction Management.

Igbinedion, V. I. (2011). Perception of Factors that Influence Students' Vocational Choice of Secretarial Studies in Tertiary Institutions in Edo State of Nigeria. European Journal of Educational Studies, 3(2), 325-337.

Instiful, G. (2010). The Teaching and Making of African Architcture in Ghana,. Proceedings of the 2010 International Conference on Architectural Research, organised by Architectural Research Centers Consortium (ARCC) and European Association for Architectural Research (EAAE).

Jensen, U. (2011). Factors Influencing Student Retention in Higher Education. Summary of influential factors in degree attainment and persistence to career or further education for at-risk/high educational need students. Honolulu: Pacific Policy Research Center.

Khan, H. U. (1987). Architectural Education: Learning from developing countries. Journal of Architectural Education, 40(2), $293-295$.

Kisi K., Shields, D. \& Shrestha, P. (2011). Identifying Factors That Influence the High School Students' Choices to Pursue Architecture, Construction and Engineering Baccalaureates.

Kolmos, A., Mejlgaard, N., Haase, S. \& Egelund H. J. (2013). Motivational Factors, Gender and Engineering Education. European Journal of Engineering Education, 38 (3), 340-358.

Kohlbacher, F. (2006). The Use of Qualitative Content Analysis in Case Study Research. Forum Qualitative Sozialforschung / Forum: Qualitative Social Research, 7(1). Retrieved on 13/03/15 from http://www.qualitative-research.net/index.php/fqs/article/view/ $75 / 153$

Maher, M. \& Macallister, H. (2013). Retention and Attrition of Students in Higher Education: Challenges in modern times to what works. Higher Education Studies, 3 (2), 62-73.

National Audit Office, UK. (2007). Staying the Course: The retention of students in higher education. London: House of Commons, London, UK. The Stationery Office.

Nelson Jr, B. H. (1974). The Decision to Study Architecture: A sociological study. Journal of Architectural Education, 27(4), 83-89.

OECD (2013). Education at a Glance 2013: OECD Indicators, OECD Publishing.

Olsen, A., Spain, J. \& Wright, R. (2008). Staying the Course: Retention and Attrition in Australian Universities. Australian Universities International Directors' Forum (AUID) Findings.

Onuoha, D. U. \& Unegbu, V. E. (2013). Career Aspiration as Predictor of Students' Performance in Cataloguing and Classification. Journal of Information Engineering and Applications, 3(3), 22-29.

Parkhouse, J. \& Ellin, D. J. (1988). Reasons for Doctors' Career Choice and Change of Choice. British Medical Journal (Clinical Research Edition), 296(6637), 1651-1653.

Purcell, K., Elias, P., Atfield, G., Behle, H., Ellison, R., Hughes, C., Livanos, I. \& Tzanakou, C. (2009). Plans, aspirations and realities: Taking stock of higher education and career choices one year on: Findings from the second Futuretrack Survey of 2006 applicants for UK Higher Education. Higher Education Career Services Unit (HECSU) and Warwick Institute for Employment Research, UK.

Silverman, M. (2004). Non-Financial Recognition- The most effective of rewards? Brighton: Institute of Employment Studies.

South African Institute of Architects (SAIA) website. (2014, August 18). URL http://saia.org.za/?page_id=73.

Stemler, S. (2001). An Overview of Content Analysis. Practical Assessment, Research \& Evaluation, 7(17). Retrieved March $13,2015$.

Stevens, G. (1996). The Historical Demography of Architects. Journal of the Society of Architectural Historian, 55(4), 435-453.

Tinto, V. (1975). Dropout from Higher Education: A theoretical synthesis of recent research. Review of Educational Research, 45(1), 89125.

Tracey, T. J. G. (2010). Relation of Interest and Self-Efficacy Occupational Congruence and Career Choice Certainty. Journal of Vocational Behavior, 76, 441-447.

Tracey, T. J. G. \& Robbins, S. B. (2006). The Interest-Major Congruence and College Success Relation: A longitudinal study. Journal of 
Vocational Behavior, 69, 64-89.

Tracey, T. J. G., Allen, J. \& Robbins, S. B. (2012). Moderation of the Relation Between Person-Environment Congruence and Academic Success: Environmental constraint, personal flexibility and method. Journal of Vocational Behavior, 80, 38-49.

Wessel, J. L., Ryan, A. M., and Oswald, F. L. (2008). The Relationship Between Objective and Perceived Fit With Academic Major, Adaptability, And Major-Related Outcomes. Journal of Vocational Behavior, 72, 363-376.

Willcoxson, L. \& Wynder, M. (2010). The relationship between choice of major and career, experience of university and attrition. Australian Journal of Education, 54(2), 175-189.

Xue, C. Q. I. \& Chen, X. (2003). Chinese architects and their practices- An analysis of a questionnaire analysis. Journal of Architectural and Planning Research, 20(4), 291-306. 